\title{
Evaluation of Self-assessed Ocular Discomfort among Students in Classrooms According to Indoor Plant Intervention
}

\author{
Hyojin Kim ${ }^{1,2}$, Ho-Hyun Kim ${ }^{3}$, Jae-Young Lee ${ }^{4}$, Yong-Won Lee ${ }^{5}$, \\ Dong-Chun Shin 6 , Kwang-Jin Kim ${ }^{7}$, and Young-Wook Lim ${ }^{8,9}$
}

ADDITIONAL INDEX WORDS. airborne particles, formaldehyde, indoor air quality, physical checkup, volatile organic compound

Summary. A cohort of sixth grade students at two newly constructed elementary schools in Seoul, South Korea, performed a self-assessment of ocular discomfort symptoms in association with indoor air quality (IAQ) by indoor plant intervention from early June to mid-Oct. 2011. Indoor plant intervention made little difference in air temperature and relative humidity, but stabilized the increasing levels of carbon dioxide. The indoor concentrations of formaldehyde and ethylbenzene showed little difference, but those of toluene and xylene showed a decreasing trend in classrooms with indoor plants. The participants in classrooms without indoor plants exhibited an increase in ocular discomfort symptoms at School A and a decrease in symptoms at School B; those in classrooms with indoor plants demonstrated a decrease in frequency at both schools. The variation of symptom severity did not follow a clear trend. Participants assessed their symptom severity of ocular discomfort with four options from three points for frequent occurrence to zero points for no occurrence. Among participants in classrooms without indoor plants, symptom severity significantly worsened at both schools as the scores increased from 1.96 to 2.17 at School A and from 2.27 to 2.34 at School B; among those in classrooms with indoor plants, symptom severity significantly lessened at School A and slightly worsened at School B as the scores decreased from 2.33 to 1.98 at School A and increased from 2.35 to 2.42 at School B. After spending the experimental duration in classrooms without indoor plants at both schools, $34.8 \%$ of participants at School A and $33.3 \%$ of participants at School B perceived their symptom severity as having increased. At Schools $A$ and B, indoor plants decreased the frequency of participants experiencing an increase of symptom severity by $13.0 \%$ and $9.7 \%$, and increased the frequency of participants reporting decrease of symptom severity by $34.8 \%$ and $22.6 \%$.

A newly constructed building contains many toxic chemicals in its indoor air in the form of airborne particles, which are emitted

The present study was carried out with the support of the "Cooperative Research Program for Agriculture Science and Technology Development (Project no. PJ010205)," Rural Development Administration, Republic of Korea.

${ }^{1}$ Division of Health Science, Department of Visual Optics, Baekseok University, Cheonan 31065, Korea ${ }^{2}$ Graduate School of Health and Welfare, Baekseok University, Seoul 06695, Korea

${ }^{3}$ Department of Integrated Environmental Systems, Pyeongtaek University, Pyeongtaek 17869, Korea

${ }^{4}$ Institute of Life Science and Resources, Kyung Hee University, Yongin 17104, Korea

${ }^{5}$ Division of Allergy-Immunology, Department of Internal Medicine, Catholic Kwandong University College of Medicine, Incheon 22711, Korea

${ }^{6}$ Department of Preventive Medicine, Yonsei University College of Medicine, Seoul 03722 , Korea

${ }^{7}$ National Institute of Horticultural and Herbal Science, Rural Development Administration, Wanju 55365, Korea

${ }^{8}$ Institute for Environmental Research, Yonsei University College of Medicine, Seoul 03722, Korea

${ }^{9}$ Corresponding author. E-mail: envlim@yuhs.ac from building materials and other indoor objects (Lim et al., 2009). These airborne particles are chiefly composed of formaldehyde and additional volatile organic compounds (VOCs) such as benzene, toluene, ethylbenzene, and xylene (BTEX) (Craighead, 1995; Sullivan et al., 2001).

Previous researchers demonstrated that the indoor levels of these airborne particles were the chief environmental factors in the health of indoor residents (Lim et al., 2006). The critical indoor level of the airborne particles varies according to the physical conditions of individuals. In the case of formaldehyde, ordinary people can detect particles at a level of $0.8 \mathrm{ppm}$ (Pohanish, 2011), but sensitive people may perceive it at a level of $0.01 \mathrm{ppm}$ (National Research Council, 1981). Children are particularly sensitive to airborne particles, as they have a relatively large lung area and respiratory volume in relation to their body mass with incomplete development of respiratory and immune systems (Lu et al., 2001; Sheets, 2000). For that reason, researchers proposed that children should avoid exposure to airborne particles in classrooms as well as at home to prevent sensory irritation like asthma, atopic dermatitis, and ocular discomfort (Arshad et al., 2001; Wahn et al., 1997).

As described above, airborne particles can cause sensory irritation in immune systems, even at a low concentration (Arts et al., 2006). Ocular discomfort is one of the most frequent sensory irritations to indoor residents caused by airborne particles (Rios et al., 2009; Wolkoff et al., 2003; Yang et al., 2001). Previous studies also found that higher indoor levels of airborne particles could bring about more severe symptoms of ocular discomfort (Brasche et al., 2005; Murphy et al., 2007; Wieslander et al., 2007). Given this, many researchers advised that facility caretakers should design indoor facilities to allow an adequate amount of fresh airflow (Lu et al., 2010) and to maintain the IAQ at an appropriate level (Kabir et al., 2011).

Some studies have reported that plants provided a positive influence on individuals, psychologically and physically (Lee and Lee, 2001; Lohr et al., 1996; Pearson et al., 1998).

\begin{tabular}{llll}
\hline $\begin{array}{l}\text { Units } \\
\text { To convert U.S. to SI, } \\
\text { multiply by }\end{array}$ & U.S. unit & SI unit & $\begin{array}{l}\text { To convert SI to U.S., } \\
\text { multiply by }\end{array}$ \\
\hline 0.3048 & $\mathrm{ft}$ & $\mathrm{m}$ & 3.2808 \\
0.0929 & $\mathrm{ft}^{2}$ & $\mathrm{~m}^{2}$ & 10.7639 \\
3.7854 & gal & $\mathrm{L}$ & 0.2642 \\
2.54 & inch(es) & $\mathrm{cm}^{2}$ & 0.3937 \\
6.4516 & inch $^{2}$ & $\mathrm{~cm}^{2}$ & 0.1550 \\
28,350 & $\mathrm{oz}$ & $\mathrm{mg}$ & $3.5274 \times 10^{-5}$ \\
1 & $\mathrm{ppb}$ & $\mu \mathrm{L}^{-3}$ & 1 \\
1 & $\mathrm{ppm}$ & $\mathrm{mL} \cdot \mathrm{m}^{-3}$ & 1 \\
$\left({ }^{\circ} \mathrm{F}-32\right) \div 1.8$ & ${ }^{\circ} \mathrm{F}$ & ${ }^{\circ} \mathrm{C}$ & $\left({ }^{\circ} \mathrm{C} \times 1.8\right)+32$
\end{tabular}


Other reports also demonstrated that individuals obtained additional benefits from plants, such as air freshness and mental comfort (Han, 2009; Lohr and Pearson-Mims, 2000). There is not yet a consensus regarding whether indoor plants are efficient in controlling the indoor level of airborne particles, due to the plant's ability to reduce the amount of airborne particles (Lim et al., 2009; Lohr and Pearson-Mims, 1996; Park et al., 2008; Wolverton and Wolverton, 1993). Although certain researchers argued that there is little relationship between indoor plants and the health complaints of indoor residents (Kim et al., 2013), others have noted that indoor plant intervention was associated with decreased sensory irritation (Hartig et al., 1992; Kaplan, 2001).

Children spend most of their daily lives in classrooms and at home. Many studies have explored the relationship between indoor plants and the health complaints of indoor residents (Han, 2009; Lee and Lee, 2001; Lohr and Pearson-Mims, 2000; Lohr et al., 1996; Pearson et al., 1998). The present study conducted an investigation for a cohort of students in growth stage on sensory irritation of the eyes in the association with IAQ by indoor plant intervention. Hence, the actual expectation of the current study is to establish appropriate environmental conditions in classrooms for the young students in elementary schools.

\section{Materials and methods}

The present study conducted a medical assessment of ocular discomfort among students at two elementary schools with intervention of IAQ adjusted by indoor plants from early June to mid-Oct. 2011. During the experimental period, mean air temperature ranged from $15{ }^{\circ} \mathrm{C}$ (October) to $25{ }^{\circ} \mathrm{C}$ (August). The current study referred to a previous report of Kim et al. (2013) regarding the arrangement of participants at facilities and the placement of indoor plants in classrooms.

Arrangement of facilities AND subJeCts. The present study arranged two categories of classrooms (Classes I and II) at two elementary schools (Schools A and B) established in early Mar. 2011. Each school provided three classrooms that had a seating capacity of 35 students: two classrooms with indoor plants (Class I) and one classroom without indoor plants (Class II). The classrooms at School A had a single wall with windows and those at School B had two (opposite) walls with windows. The classrooms in both schools had the same rectangular dimensions of $7.7 \times$ $9 \mathrm{~m}$ (width $\times$ length) and were equipped with individual systems of artificial ventilation and air conditioning. Indoor air of each classroom was controlled at the same status in thermal condition and air pollutant level before the experimental period by the individual systems and then was not interfered with during the entire period except by opening windows. The present study recruited sixth grade students who would attend school during the entire experimental duration (including vacation but not including Saturdays and Sundays) without cessation from the whole students of each classroom. Then, the authors arranged 46 participants in two classrooms with indoor plants (Class I) and 23 participants in one classroom without indoor plants (Class II) at School A; the authors organized 31 participants in two classrooms with indoor plants (Class I) and 15 participants in one classroom without indoor plants at School B (Fig. 1).

INDOOR PLANT PLACEMENT. The current research followed the descriptions from previous reports regarding the types, quantity, and method of indoor plant placement. The present researchers placed indoor plants in the classrooms of Class I at both schools for over 12 weeks (from 7 Mar. to 31 May) to acclimate the plants to an indoor environment, and removed them for over 3 weeks (from 1 to 23 June) to diminish the environmental damage to the plants before practical examination (Kil et al., 2008). Then, indoor plants were again installed in the classrooms on 24 June and placed until the end of the experimental period (14 Oct. 2011).

The authors classified indoor plants into two categories, large and small ones. Based on a previous report by Lee and Kim (2005), a large plant was one with a leaf area of 3000 to $5000 \mathrm{~cm}^{2}$ and a small plant was one with a leaf area of less than $1000 \mathrm{~cm}^{2}$. Considering the capacity of formaldehyde decomposition, previous researchers recommended the type of indoor plants suitable. Lady palm (Rhapis excelsa), rubber plant (Ficus elastica), heavenly bamboo (Nandina domestica), and fatsi (Fatsia japonica) were included as large plants; and golden pothos (Epipremnum aureum), tiny ardisia (Ardisia psilla), angel's tears (Soleirolia soleirolii), and english ivy (Hedera helix) were included as small plants (Kil et al., 2008; Kim et al., 2009; Lee and Kim, 2005). Large plants were potted in pots sized $30 \times 41 \mathrm{~cm}$ [width $\times$ height $(28.976$ $\mathrm{L})]$ or $24 \times 23.5 \mathrm{~cm}(10.626 \mathrm{~L})$, and small plants were potted in pots sized $16 \times 15 \mathrm{~cm}(3.815 \mathrm{~L})$. The pots were filled with bark, sand, and growth media (Sunshine Mix-4; Sun Gro Horticulture, Agawam, MA) at a volume rate of $1: 1: 5$, and then planted. Then, more than one large plant and one small plant were placed in an area of $6 \mathrm{~m}^{2}$ (Table $\mathrm{l}$ ), following the description from a previous report (Lee and Kim, 2005). Considering the distinctive layout of the classrooms and the location of indoor objects, the authors placed indoor plants at the back of the classrooms in School A and at the windows in the classrooms in School B (Fig. 2).

MEASUREMENT OF CONDITIONS AND QUALITY OF INDOOR AIR. The present study observed the conditions and quality of indoor air in the classrooms at both schools throughout the experimental duration.

\begin{tabular}{|c|c|c|c|}
\hline \multirow{2}{*}{} & \multicolumn{2}{|c|}{ Class I (2 classrooms) } & Class II (1 classroom) \\
\cline { 2 - 5 } & \multicolumn{2}{|c|}{ With plants } & Without plants \\
\hline \multirow{2}{*}{ School A } & \multicolumn{2}{|c|}{$(\mathrm{n}=46)$} & $(\mathrm{n}=23)$ \\
\cline { 2 - 5 } & 23 & 23 & 23 \\
\hline \multirow{2}{*}{ School B } & \multicolumn{2}{|c|}{$(\mathrm{n}=31)$} & $(\mathrm{n}=15)$ \\
\cline { 2 - 5 } & 16 & 15 & 15 \\
\hline
\end{tabular}

Fig. 1. Arrangement of participants in classrooms at both elementary schools in association with indoor plant intervention. Properties of classrooms: size $=7.7 \mathrm{~m}$ width $\times 9$ m length $(25.26 \times 29.53 \mathrm{ft})$, seating capacity $=35$ students. 
Table 1. Kinds and quantity of indoor potted plants installed in each classroom for the evaluation of self-assessed ocular discomfort of participants.

\begin{tabular}{llcc}
\hline Classification $^{\mathbf{z}}$ & Common name & Size $[\text { diam } \times \mathbf{h t}(\mathbf{c m})]^{\mathbf{y}}$ & Plants (no.) \\
\hline Large plants & Lady palm & $30 \times 41$ & 3 \\
& Rubber plant & $30 \times 41$ & 3 \\
& Heavenly bamboo & $24 \times 23.5$ & 2 \\
& Fatsi & $24 \times 23.5$ & 2 \\
& & & 2 \\
Small plants & Golden pothos & $18 \times 15$ & 2 \\
& Tiny ardisia & $18 \times 15$ & 3 \\
& Angel's tears & $18 \times 15$ & 3 \\
\hline
\end{tabular}

${ }^{2}$ Large plants = leaf area of 3000 to $5000 \mathrm{~cm}^{2} /$ plant, small plants = leaf area of less than $1000 \mathrm{~cm}^{2} /$ plant; $1 \mathrm{~cm}^{2}=$ 0.1550 inch $^{2}$

${ }^{\mathrm{y}} 1 \mathrm{~cm}=0.3937$ inch
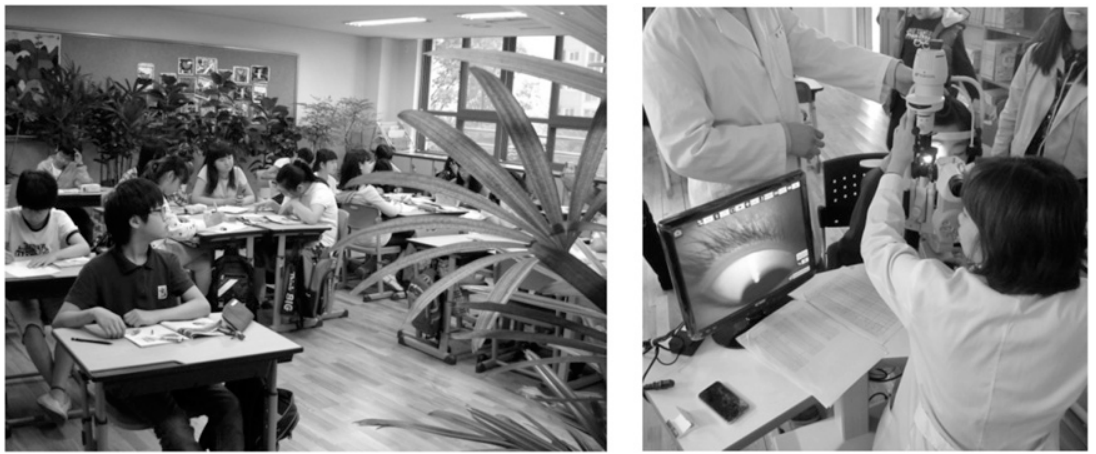

Fig. 2. Overall views of the classroom with indoor plants (left) and the state of physical control up on the ocular discomfort for subjects (right).

The authors observed indoor air conditions by recording air temperature $\left({ }^{\circ} \mathrm{C}\right)$, relative humidity (percent), and the levels of carbon dioxide $\left[\mathrm{CO}_{2}\right.$ (milliliters per cubic meter)], and evaluated IAQ by measuring the indoor concentrations (microliters per cubic meter) of formaldehyde and BTEX. The present study completed the first observation before indoor plant placement (from 6 to 24 June), and conducted the second observation 3 months after indoor plant placement (from 26 Sept. to 14 Oct.). Each observation consisted of nine measurement days over 3 weeks (every Monday, Wednesday, and Friday). On every measurement day, the conditions and quality of indoor air were recorded at 9:00 AM and 1:00 PM with the participants in the state of usual activity. To prevent any variance from outdoors, indoor air was regulated with doors and windows in opened minimally and mechanical ventilation in a halted state from early morning to the end of the measurement time.

Air temperature and relative humidity were recorded at one site at a height of $1.5 \mathrm{~m}$ above floor level in the midpart of the classrooms (less than $4 \mathrm{~m}$ from the plants) using a digital recorder (950; Testo, Lenzkirch, Germany). The level of $\mathrm{CO}_{2}$ was measured at two sites (fore and back sites, 3 to $6 \mathrm{~m}$ from the plants) using a digital gas analyzer (Witt Gastetechnik, Witten, Germany).

The current study measured the concentrations of formaldehyde and BTEX at two sites in the classrooms (fore and back sites, 3 to $6 \mathrm{~m}$ from the plants) as follows. The present study installed a personal air sampler (Minipump $\sum \mathrm{MP}-100 \mathrm{H}$; Shibata, Saitama, Japan) in series connection with an ozone scrubber cartridge (Waters Corp., Milford, MA) containing $350 \mathrm{mg}$ of silica gel coated with $100 \mathrm{mg}$ of 2,4-dinitrophenylhydrazine reagent. Then, indoor air was absorbed into the sampler at a height of $1.5 \mathrm{~m}$ above floor level at a flow rate of $0.5 \mathrm{~L} \cdot \mathrm{min}^{-1}$ for $30 \mathrm{~min}$ and the concentration of formaldehyde was measured using high-performance liquid chromatography equipped with ultraviolet absorption (Alliance 2690 and 2487, Waters Corp.).

The present study also measured the indoor concentrations of BTEX through a solid thermal desorption method (Kim et al., 2010, 2011; Lim et al., 2009). The authors collected indoor air containing BTEX using another personal air sampler (Minipump MP-30, Shibata) equipped with a sorbent tube for trapping $[1 / 4$ inch $\times 10 \mathrm{~cm}$ stainless steel (Tenax-TA; Supelco, Bellefonte, PA)] at a flow rate of $10 \mathrm{~L} \cdot \mathrm{min}^{-1}$ for $30 \mathrm{~min}$, and analyzed the indoor concentrations of BTEX using gas chromatography (G-14B; Shimadzu, Tokyo, Japan). The probability of the calibration curve was managed at $0.5 \%$ level for formaldehyde and BTEX. The extraction efficiencies were $92 \%$ to $105 \%$ for formaldehyde and $90 \%$ to $113 \%$ for BTEX.

ASSESSMENT OF OCULAR DISCOMFORT. All participants were assessed via interview and physical checkup focused on ocular discomfort symptoms such as soreness, itch, dryness, grittiness, and redness. A medical expert in preventive medicine interviewed all the participants to complete a questionnaire devised by previous researchers (Wieslander et al., 1999) twice per day at 9:00 $\mathrm{AM}$ and 1:00 PM on the 9 measurement days over 3 weeks (every Monday, Wednesday, and Friday) during each observation session. The questionnaire was composed of the items about environmental conditions in the classrooms and the symptom severity of ocular discomfort. The present study measured the degree of air temperature, relative humidity, and $\mathrm{CO}_{2}$ as environmental conditions and checked up on the severity of eye soreness, itch, dryness, grittiness, and redness for participants as symptom severities. Participants answered questions about their symptom severity of ocular discomfort during the last 2 weeks with four response options: three points for "yes" with frequent occurrence, two points for "yes" with occasional occurrence, one point for "no" with little occurrence and zero points for "no" with zero occurrence. After obtaining scores, the current researchers calculated mean values for each class to compare the symptom severity of ocular discomfort with an index proposed by Chalmers et al. (2010). An expert in ophthalmology approved the reliability 
for the questionnaire to maintain the Cronbach alpha coefficient above 0.70 using the physical checkup medical records for each participant (Fig. 2).

STATISTICAL ANALYSIs. The present study observed the differences in indoor air status and the prevalence of ocular discomfort between the groups using chi-square tests in two by two tables. The authors also compared the differences in symptom severity by indoor plant intervention using a Mann-Whitney $U$ test. The statistical probability was managed at the levels of 0.05 and 0.01 .

\section{Results}

The present study evaluated the status of classrooms with indoor plant intervention by measuring the condition and quality of indoor air as shown in Table 2.

Observing the indoor conditions over time in classrooms without indoor plants, the authors found a decrease in air temperature and relative humidity, and detected an increase in the level of $\mathrm{CO}_{2}$. Air temperature decreased from 26.0 to $24.8^{\circ} \mathrm{C}$ and relative humidity from $54 \%$ to $49 \%$. However, the level of $\mathrm{CO}_{2}$ increased from 1350 to $1597 \mathrm{~mL} \cdot \mathrm{m}^{-3}$. The intervention of indoor plants did not change the decreasing tendencies in air temperature or relative humidity, but stabilized $\mathrm{CO}_{2}$ level in classrooms with indoor plants.

The authors detected various tendencies in the indoor concentrations of formaldehyde and BTEX. In the classrooms without indoor plants, the indoor concentration of formaldehyde decreased from 31.12 to $11.96 \mu \mathrm{L} \cdot \mathrm{m}^{-3}$ during the experimental duration. The levels of benzene and ethylbenzene decreased from 5.74 to $4.48 \mu \mathrm{L} \cdot \mathrm{m}^{-3}$ and from 9.38 to 7.36 $\mu \mathrm{L} \cdot \mathrm{m}^{-3}$, respectively; but the level of toluene increased from 66.01 to 89.75 $\mu \mathrm{L} \cdot \mathrm{m}^{-3}$. The level of xylene remained constant at around $7.70 \mu \mathrm{L} \cdot \mathrm{m}^{-3}$ during the entire experimental duration. The intervention of indoor plants made little differences in the decreasing tendency of the levels of formaldehyde and benzene, but facilitated the decreasing trend of the level of benzene. Indoor plant intervention reversed the trend in the concentrations of toluene and xylene, altering from increasing to decreasing (Table 2 ).

Table 3 exhibits the variation in the frequency of participants reporting ocular discomfort symptoms over time by indoor plant intervention.

At School A, there was a decrease in the frequency of all the symptoms of ocular discomfort, regardless of indoor plant intervention, except for the symptom of gritty eyes. After spending the experimental duration, participants reporting gritty eyes increased from $8.7 \%$ to $13.0 \%$ in classrooms without indoor plants, but decreased from $4.4 \%$ to $2.3 \%$ in classrooms with indoor plants. The variation in the frequency of ocular discomfort symptoms at School B followed a different pattern than it did at School A. The frequency of participants increased for all the symptoms of ocular discomfort over time except the symptom of gritty eyes. The participants reporting gritty eyes remained constant at $6.7 \%$ during the experimental duration. Indoor plant intervention decreased the frequency of participants reporting ocular discomfort symptoms with some exceptions. The participants reporting sore eyes remained and the participants reporting gritty eyes increased in their frequency after spending the period.

Additionally, the present study assessed changes in the frequency of participants reporting one or more symptoms of ocular discomfort over time. In classrooms without indoor plants, the participants reporting symptoms decreased at School A from $39.1 \%$ to $30.4 \%$ but increased at School B from $33.3 \%$ to $40.0 \%$. However, indoor plant intervention appeared to cause a decrease in the participants reporting ocular discomfort symptoms at both schools, from $39.1 \%$ to $26.1 \%$ at School A and from $41.9 \%$ to $32.3 \%$ at School B (Table 3 ).

Participants evaluated their symptom severity with numeric scores for overall symptoms of ocular discomfort, and those scores were calculated into mean values to compare symptom severity. After spending the experimental period at School A, participants in classrooms without indoor plants experienced an increase in overall symptom severity, with scores increasing from 1.96 to 2.17 . The participants spending the period in classrooms with indoor plants reported their symptom severity decreased from 2.33 to 1.88 . However, participants at School B exhibited little change in their symptom severity regardless of indoor plant intervention (Fig. 3).

After the experimental duration, participants experienced changes in overall symptom severity of ocular discomfort. In the classrooms without indoor plants, $34.8 \%$ and $33.3 \%$

Table 2. Mean value changes in the condition of thermal environment and the concentrations of indoor air pollutants in the classrooms at the newly built elementary schools according to indoor plant intervention.

\begin{tabular}{|c|c|c|c|c|c|c|c|}
\hline \multirow[b]{3}{*}{ Classification $^{z}$} & \multirow[b]{3}{*}{ Item $^{\mathrm{z}}$} & \multicolumn{2}{|c|}{ Without plants ${ }^{\mathrm{y}}$} & \multirow[b]{3}{*}{$P$ value } & \multicolumn{3}{|c|}{ With plants } \\
\hline & & First & Second & & First & Second & \multirow[b]{2}{*}{$P$ value } \\
\hline & & \multicolumn{2}{|c|}{$($ Mean $\pm \mathrm{SE})$} & & \multicolumn{2}{|c|}{$($ Mean $\pm \mathrm{SE})$} & \\
\hline condition & Humidity (\%) & $54 \pm 1.1$ & $49 \pm 1.3$ & 0.0233 & $57 \pm 1.1$ & $50 \pm 1.8$ & 0.0268 \\
\hline & $\mathrm{CO}_{2}$ level $\left(\mathrm{mL} \cdot \mathrm{m}^{-3}\right)$ & $1,350 \pm 96.9$ & $1,597 \pm 90.2$ & 0.0437 & $1,360 \pm 85.1$ & $1,291 \pm 82.3$ & 0.0632 \\
\hline & Toluene & $66.01 \pm 6.31$ & $89.75 \pm 12.16$ & 0.0085 & $75.18 \pm 7.13$ & $38.57 \pm 7.65$ & 0.0096 \\
\hline & Ethylbenzene & $9.38 \pm 1.59$ & $7.36 \pm 1.29$ & 0.0354 & $7.86 \pm 1.36$ & $5.74 \pm 1.27$ & 0.0088 \\
\hline & Xylene & $7.44 \pm 1.31$ & $7.60 \pm 0.58$ & 0.0626 & $7.77 \pm 1.20$ & $6.70 \pm 0.66$ & 0.0133 \\
\hline
\end{tabular}

${ }^{\mathrm{z}} 1 \mu \mathrm{L} \cdot \mathrm{m}^{-3}=1 \mathrm{ppb},\left(1.8 \times{ }^{\circ} \mathrm{C}\right)+32={ }^{\circ} \mathrm{F}, 1 \mathrm{~mL} \cdot \mathrm{m}^{-3}=1 \mathrm{ppm}, \mathrm{CO}_{2}=$ carbon dioxide.

${ }^{y}$ First $=$ first observation (July), second $=$ second observation (late September to mid-October). 
Table 3. Variation in the frequency of subjects perceiving ocular discomfort symptoms by self-assessment as reported during past 2 weeks in the classrooms of the elementary schools according to indoor plant placement.

\begin{tabular}{|c|c|c|c|c|c|c|c|c|}
\hline \multirow[b]{3}{*}{ Symptoms of ocular discomfort } & \multicolumn{4}{|c|}{ School A } & \multicolumn{4}{|c|}{ School B } \\
\hline & \multicolumn{2}{|c|}{$\begin{array}{l}\text { Without plants } \\
(\mathrm{n}=23)\end{array}$} & \multicolumn{2}{|c|}{$\begin{array}{l}\text { With plants } \\
(\mathrm{n}=46)\end{array}$} & \multicolumn{2}{|c|}{$\begin{array}{l}\text { Without plants } \\
\quad(\mathrm{n}=15)\end{array}$} & \multicolumn{2}{|c|}{$\begin{array}{l}\text { With plants } \\
\quad(\mathrm{n}=31)\end{array}$} \\
\hline & First $^{\mathrm{z}}$ & Second & First & Second & First & Second & First & Second \\
\hline \multicolumn{9}{|l|}{ Symptom for the past 2 weeks } \\
\hline Sore eyes & 13.0 & 8.7 & 10.9 & 6.5 & 13.3 & 20.0 & 12.9 & 12.9 \\
\hline & \multicolumn{2}{|c|}{$(1.000)^{\mathrm{y}}$} & \multicolumn{2}{|c|}{$(0.714)$} & \multicolumn{2}{|c|}{$(1.000)$} & \multicolumn{2}{|c|}{$(1.000)$} \\
\hline Dry eyes & 17.4 & 13.0 & 13.4 & 10.9 & 13.3 & 20.0 & 16.1 & 12.9 \\
\hline & \multicolumn{2}{|c|}{$(1.000)$} & \multicolumn{2}{|c|}{$(1.000)$} & \multicolumn{2}{|c|}{$(1.000)$} & \multicolumn{2}{|c|}{$(1.000)$} \\
\hline \multirow[t]{2}{*}{ Gritty eyes } & 8.7 & 13.0 & 4.4 & 2.3 & 6.7 & 6.7 & 6.5 & 12.9 \\
\hline & \multicolumn{2}{|c|}{$(1.000)$} & \multicolumn{2}{|c|}{$(1.000)$} & \multicolumn{2}{|c|}{$(1.000)$} & \multicolumn{2}{|c|}{$(0.671)$} \\
\hline Eye redness & 13.0 & 8.7 & 10.9 & 4.4 & 13.3 & 20.0 & 12.9 & 9.7 \\
\hline 0.05 & \multicolumn{2}{|c|}{0.413} & \multicolumn{2}{|c|}{0.288} & \multicolumn{2}{|c|}{0.514} & \multicolumn{2}{|c|}{0.355} \\
\hline 0.01 & \multicolumn{2}{|c|}{0.526} & & 72 & & & & \\
\hline
\end{tabular}

${ }^{2}$ First $=$ first observation (July), second $=$ second observation (late September to mid-October).

yumeric value in the parenthesis is the $r$ value by chi-square test.

${ }^{\mathrm{x}}$ Least significant difference between the values of two observation times for each or overall ocular discomfort symptom.

of participants reported their symptom severity worsened at Schools A and B. Whereas $21.7 \%$ and $13.3 \%$ of participants perceived their symptom severity improved. Indoor plant intervention decreased the frequency of participants who reported their symptom severity worsened by $13.0 \%$ at School A and $9.7 \%$ at School B, and increased the frequency of participants who reported their symptom severity improved by $34.8 \%$ at School $A$ and $22.6 \%$ at School B (Fig. 4).

\section{Discussion}

The present study carried out medical examination of ocular discomfort symptoms among elementary school students in association with IAQ by indoor plant intervention.

After the experimental period, the overall status of indoor air was compared in association with IAQ by indoor plant intervention. Air temperature and relative humidity decreased in all classrooms regardless of indoor plant intervention. The level of $\mathrm{CO}_{2}$ increased in the classrooms without indoor plants, but remained constant in the classrooms with indoor plants. The current study conducted its first observation in July (high temperature and humid season) and the second observation in late September to mid-October (cool temperature and dry season). For that reason, the authors could postulate seasonal conditions to be the chief factor influencing air temperature and relative humidity. Choi et al. (2006) previously reported the variation in indoor air through measurement at different times. However, indoor plant intervention stabilized the level of $\mathrm{CO}_{2}$.

According to previous studies, newly constructed buildings contain high levels of VOCs in indoor air (Craighead, 1995; Lim et al., 2009; Sullivan et al., 2001). As such, the high indoor concentrations of VOCs at the first observation time could be regarded as typical levels for a newly constructed building. Many factors seemed to be involved in the change in the indoor concentrations of VOCs at the second observation time. Lu et al. (2010) theorized that adequate fresh air flow from the outdoors reduced the indoor levels of VOCs to satisfactory degree, and $\mathrm{Kim}$ et al. (2013) observed that indoor plant intervention made little difference in the indoor concentration of formaldehyde. However, other previous researchers noted that indoor plant intervention was an effective method to decrease the levels of VOCs in indoor facilities ( $\mathrm{Lim}$ et al., 2009; Lohr and Pearson-Mims, 1996; Park et al., 2008; Wolverton and Wolverton, 1993). The present study concluded that the decrease in the indoor levels of VOCs was brought about by adequate fresh air flow from outdoors, and facilitated by indoor plant intervention (Table 2 ).

After spending the experimental period in the classrooms without indoor plants, participants' ocular discomfort symptoms decreased at School A, but increased at School B. Participants in the classrooms with indoor plants exhibited a decrease in most ocular discomfort symptoms at both schools. In summary, the present study could not find a decreasing trend in symptoms of ocular discomfort in classrooms without indoor plants, but found a decrease in symptoms in classrooms with indoor plants. While some reports indicate that indoor plant intervention improve the IAQ of indoor facilities (Lim et al., 2009; Lohr and Pearson-Mims, 1996; Park et al., 2008; Wolverton and Wolverton, 1993), others indicate that IAQ is a major factor influencing the health of indoor residents (Lim et al., 2006). In addition, exposure to airborne particles leads to sensory irritation in the eyes, such as soreness, itch, dryness, grittiness, and redness (Arts et al., 2006; Brightman and Moss, 2001; Murphy et al., 2007; 


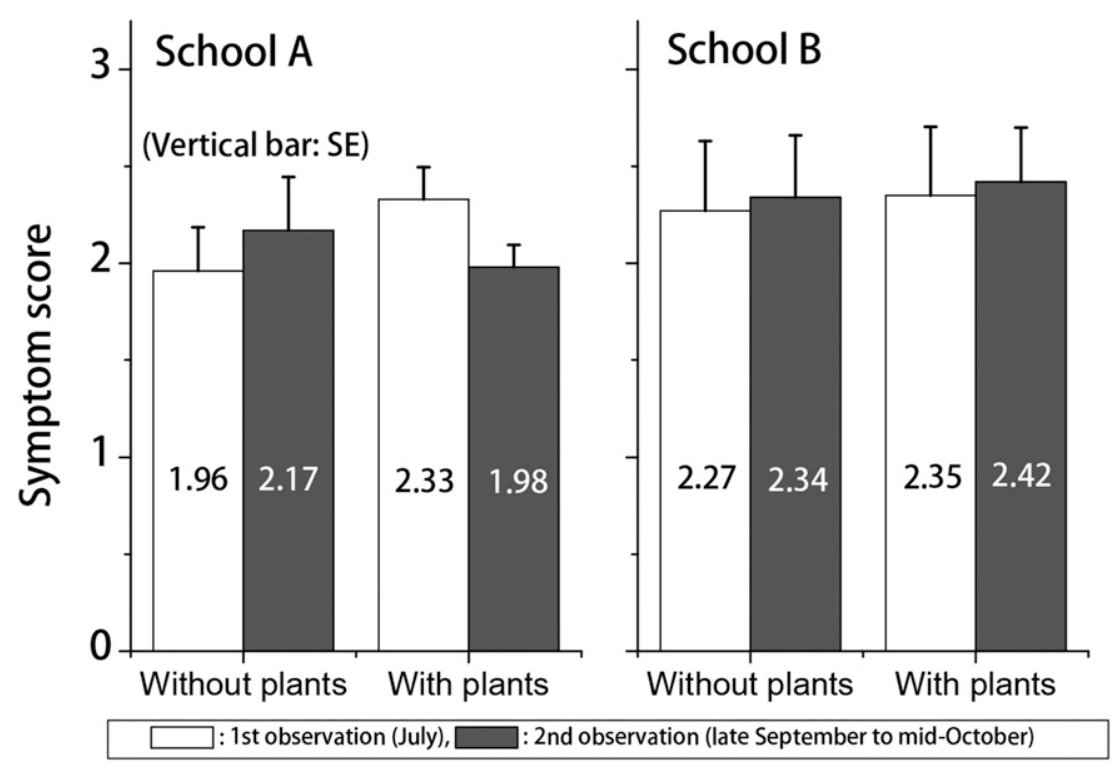

Fig. 3. Mean score changes of symptom severity through Mann-Whitney $U$ test for the participants perceiving ocular discomfort in the classrooms of the elementary schools in association with indoor plant intervention. Symptom severity scores: 3 ("yes" with frequent occurrence), 2 ("yes" with occasional occurrence), 1 ("no" with little occurrence), and 0 ("no" with zero occurrence).

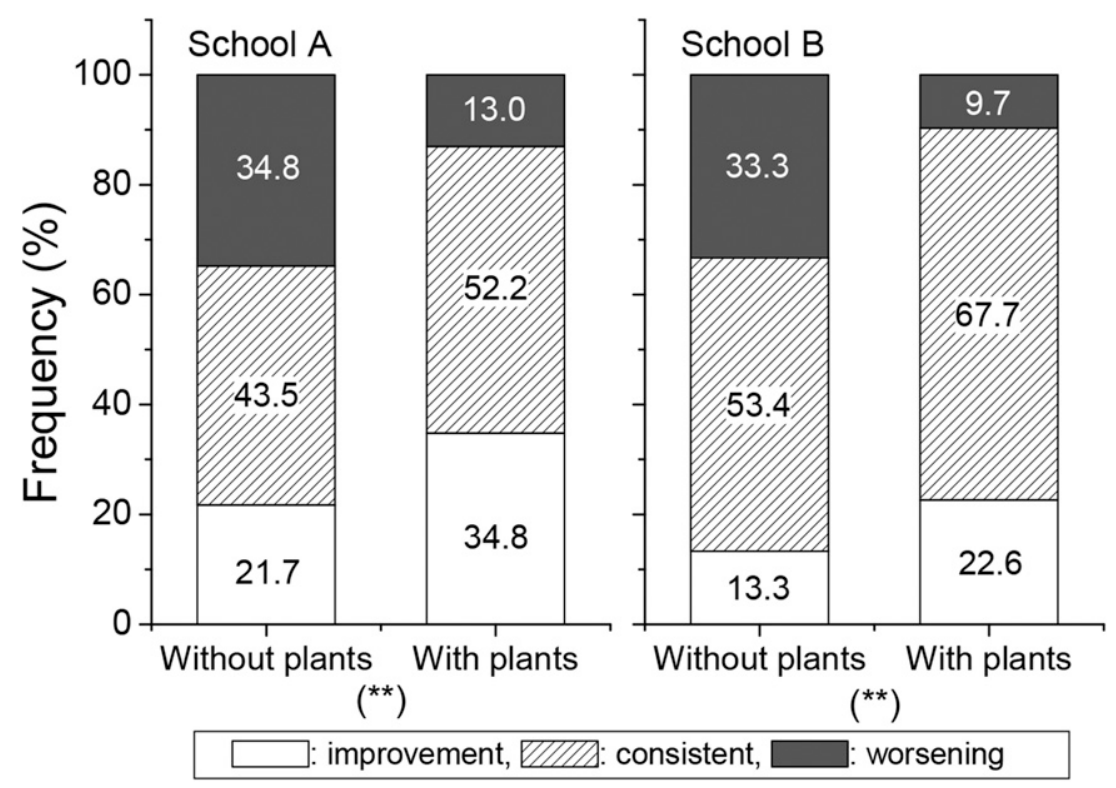

Fig. 4. Frequency changes of symptom severity of ocular discomfort by selfassessment for the participants in the classroom of the elementary schools. Asterisk in the parenthesis indicates a significant difference at the level of $0.01\left(^{* *}\right)$.

Papas, 1998). The current researchers proposed that indoor plant intervention could decrease the frequency of individuals perceiving ocular discomfort symptoms by IAQ improvement (Table 3).

Indoor plant intervention did not create a regular trend in the variation of overall symptom scores, as seen in Fig. 3, but demonstrated a clear tendency in the overall change in symptom severity, as seen in Fig. 4.

Among participants perceiving the symptoms of ocular discomfort, more than $30 \%$ reported symptoms in the classrooms without indoor plants, but fewer than $15 \%$ reported symptoms in the classrooms with indoor plants. It was previously reported that plants provided positive effects to human beings, both physically and mentally (Lohr et al., 1996; Pearson et al., 1998). Particularly, indoor plant intervention resulted in a positive perception among indoor residents through improving IAQ (Lee and Lee, 2001; Lohr and PearsonMims, 2000). Other studies also recommended indoor plant intervention decreased sensory irritation of indoor residents (Hartig et al., 1992; Kaplan, 2001). Considering all of these findings, the authors postulated that indoor plant intervention made participants perceive improvement in their symptom severity of ocular discomfort through IAQ improvement. Nevertheless, the symptom severity of ocular discomfort seems to be diverse, influenced by many internal and external factors, such as wind, dust, smoke, individual sensitivity, gender, and other psychological factors (Kjaegaard et al., 2004; McMonnies and Ho, 1991; Wolkoff et al., 2003) (Figs. 3 and 4 ).

In conclusion, the present study postulated that indoor plant intervention can decrease the symptom severity of ocular discomfort in participants through IAQ improvement. Arts et al. (2006) noted that the relationship between IAQ improvement and indoor resident health was such that indoor air pollutants commonly led indoor residents to experience sensory irritation in the eyes, even at a low concentration of pollutants. According to previous reports on airborne particles and sensory irritation of ocular discomfort, the critical levels varied among individuals, from ordinary to sensory people (National Research Council, 1981; Pohanish, 2011). For that reason, the authors proposed to establish practical guidelines for controlling IAQ in indoor facilities including the classrooms in elementary schools to prevent sensory irritation in the eyes caused by insufficient levels of IAQ (Tables 2 and 3; Figs. 3 and 4).

\section{Literature cited}

Arshad, S.H., S.M. Tariq, S. Matthews, and E. Hakim. 2001. Sensitization to common allergens and its association with allergic disorders at age 4 years: A whole population birth cohort study. Pediatrics 108:460-467.

Arts, J.H.E., M.A.J. Rennen, and C. de Heer. 2006. Inhaled formaldehyde: 
Evaluation of sensory irritation in relation to carcinogenicity. Regulat. Toxicol. Pharmacol. 44:144-160.

Brasche, C., M.C. Bullinger, and A. Petrovitch. 2005. Self-reported eye symptoms and related diagnostic findings: Comparison of risk factors profiles. Indoor Air 15(suppl. 10):56-64.

Brightman, H.S. and N. Moss. 2001. Sick building syndrome studies and the compilation of normative and comparative values, p. 3.1-3.32. In: J.D. Spengler, J.M. Samet, and J.F. McCarthy (eds.). Indoor air quality handbook. lst ed. McGraw-Hill, New York, NY.

Chalmers, R.L., C.G. Begley, and B. Caffery. 2010. Validation of the 5-item dry eye questionnaire (DEQ-5): Discrimination across self-assessed severity and aqueous tear deficient dry eye diagnoses. Cont. Lens Anterior Eye 33:55-60.

Choi, J.Y., D.B. Yang, H.J. Ju, K.T. Kim, G.H. Hong, and K.H. Shin. 2006. Distribution of organophosphorus pesticides in Asan bay, Korea. Korea Soc. Marine Environ. Eng. 9:176-186.

Craighead, J.E. 1995. Indoor air quality and pollution, p. 29-39. In: J.E. Craighead (ed.). Pathology of environmental and occupational disease. lst ed. Mosby, St. Louis, MO.

Han, K.T. 2009. Influence of limitedly visible leafy indoor plants on the psychology, behavior, and health of students at a junior high school in Taiwan. Environ. Behav. 41:658-692.

Hartig, T., M. Mang, and W. Evans. 1992. Restorative effects of natural environment experiences. Environ. Behav. 23:3-26.

Kabir, E., K.H. Kim, J.R. Sohn, B.Y. Kweon, and J.H. Shin. 2011. Indoor air quality assessment in child care and medical facilities in Korea. Environ. Monit. Assess. 184:6359-6049.

Kaplan, S. 2001. Mediation, restoration, and the management of mental fatigue. Environ. Behav. 33:480-506.

Kil, M.J., K.J. Kim, J.K. Cho, and C.H. Park. 2008. Formaldehyde gas removal effects and physiological responses of Fatsia japonica and Epiprenum aureum according to various light intensity. Korean J. Hort. Technol. Sci. 26:189-196.

Kim, H.H., J.Y. Lee, H.J. Kim, Y.W. Lee, K.J. Kim, J.H. Park, D.C. Shin, and Y.W. Lim. 2013. Impact of foliage plant interventions in classrooms on actual air quality and subjective health complaints. J. Jpn. Soc. Hort. Sci. 82:255-262.

Kim, H.H., J.Y. Lee, J.Y. Yang, K.J. Kim, Y.J. Lee, D.C. Shin, and Y.W. Lim. 2011.
Evaluation of indoor air quality and health related parameters in office buildings with or without indoor plants. J. Jpn. Soc. Hort. Sci. 80:96-102.

Kim, K.J., M.I. Jeong, D.W. Lee, J.S. Song, H.D. Kim, E.H. Yoo, S.J. Jeong, S.W. Han, S.J. Kays, Y.W. Lim, and H.H. Kim. 2010. Variation in formaldehyde removal efficiency among indoor plant species. HortScience 45:1489-1495.

Kim, K.J., M.J. Kil, M.I. Jeong, H.D. Kim, E.H. Yoo, S.J. Jeong, C.H. Park, and K.C. Son. 2009. Determination of the efficiency of formaldehyde removal according to the percentage volume of pot plants occupying a room. Korean J. Hort. Technol. Sci. 27:305-311.

Kjaegaard, S.K., A. Hempel-Jørgensen, L. Mølhave, K. Andersson, J.E. Juto, and G. Stridh. 2004. Eye trigeminal sensitivity, tear film stability and conjunctival epithelium damage in 182 non-allergic, nonsmoking Danes. Indoor Air 14:200-207.

Lee, J.H. and C.R. Lee. 2001. The effect of recovery from psychological stress by interior landscape spaces. J. Korea Inst. Landscape Architecture 28:106-113. (In Korean with English abstract).

Lee, J.H. and T.H. Kim. 2005. Function of nature purification by plants for the indoor air of freshness and safety, p. 7188. Symp. Horticultural Fair 2005. Korean Soc. Hort. Sci., Iseo-myeon, South Korea. (In Korean).

Lim, Y.W., H.H. Kim, J.Y. Yang, K.J. Kim, J.Y. Lee, and D.C. Shin. 2009. Improvement of indoor air quality by houseplants in new-built apartment buildings. J. Jpn. Soc. Hort. Sci. 78:456-462.

Lim, Y.W., J.Y. Yang, H.H. Kim, Y.G. Lee, Y.S. Kim, S.K. Kang, J.R. Son, Y.M. Roh, and D.C. Shin. 2006. Health risk assessment in terms of VOC at newlybuilt apartment house. J. Korean Soc. Indoor Environ. 3:211-223. (In Korean with English abstract).

Lohr, V.I. and C.H. Pearson-Mims. 1996. Particulate matter accumulation on horizontal surface in interiors: Influence of foliage plants. Atmos. Environ. 30:2565-2568.

Lohr, V.I. and C.H. Pearson-Mims. 2000. Physical discomfort may be reduced in the presence of interior plants. HortTechnology 10:53-58.

Lohr, V.I., C.H. Pearson-Mims, and G.K. Goodwin. 1996. Interior plants may improve worker productivity and reduce stress in a windowless environment. J. Environ. Hort. 14:97-100.

Lu, C., D.E. Knutson, J. Fisker-Andersen, and R.A. Fenske. 2001. Biological monitoring survey of organophosphorus pesticide exposure among pre-school children in the Seattle metropolitan area. Environ. Health Perspect. 109:299-303.

Lu, Y., J. Lui, B. Lu, A. Jiang, and C. Wan. 2010. Study on the removal of indoor VOCs using biotechnology. J. Hazard. Mater. 182:204-209.

McMonnies, C.W. and A. Ho. 1991. Conjunctival hyperaemia in non-contact lens wearers. Acta Ophthalmologica 69:799-801.

Murphy, P.J., J.S. Lau, M.M. Sim, and R.L. Woods. 2007. How red is a white eye? Clinical grading of normal conjunctival hyperaemia. Eye (Lond.) 21:633-638.

National Research Council. 1981. Formaldehyde and other aldehydes. National Academy Press, Washington, DC.

Papas, E. 1998. On the relationship between soft contact lens oxygen transmissibility and induced limbal hyperaemia. Exp. Eye Res. 67:125-131.

Park, S.Y., J.S. Song, H.D. Kim, and K.C. Son. 2008. Effects of interior plant capes on indoor environments and stress level of high school students. J. Jpn. Soc. Hort. Sci. 77:447-454.

Pearson, R., L.G. Tassinary, R.S. Ulrich, M.R. Hebl, and M.G. Alexander. 1998. The view from the road: Implications for stress recovery and immunization. J. Environ. Psychol. 18:113-139.

Pohanish, R.P. 2011. Formaldehyde, p. 1350-1353. In: R.P. Pohanish (ed.). Sittig's handbook of toxic and hazardous chemicals and carcinogens. 6th ed. William Andrew Publ., Waltham, MA.

Rios, J.L., J.L. Boechat, A. Gioda, C.Y. dos Santos, F.R. de A. Neto, and J.R.L. e Silva. 2009. Symptoms prevalence among office workers of a sealed versus a non-sealed building: Association to indoor air quality. Environ. Intl. 35:1136-1141.

Sheets, L.P. 2000. A consideration of agedependent differences in susceptibility to organophosphorus and pyrethroid insecticide. Neurotoxicology 21:57-63.

Sullivan, J.B., Jr., M.D. Van Ert, G.R. Krieger, and B.O. Brooks. 2001. Indoor environmental quality and health, p. 669704. In: J.B. Sullivan, Jr. and G.R. Krieger (eds.). Clinical environmental health and toxic exposure. 2nd ed. Lippincott Williams Wilkins, Philadelphia, PA.

Wahn, U., S. Lau, R. Bergmann, M. Kulig, J. Forster, K. Bergmann, C.P. Bauer, and I. Guggenmoos-Holzmann. 1997. Indoor allergen exposure is a risk factor for sensitization during the first three years of life. J. Allergy Clin. Immunol. 99:763-769. 
Wieslander, G., D. Norbäck, and P. Venge. 2007. Changes of symptoms, tear film stability and eosinophilic cationic protein in nasal lavage fluid after re-exposure to a damp office building with a history of flooding. Indoor Air 17:19-27.

Wieslander, G., D. Norbäck, K. Nordstrom, R. Walimder, and P. Venge. 1999. Nasal and ocular symptoms, tear film stability and biomarkers in nasal lavage, in relation to building-dampness and building design in hospitals. Intl. Arch. Occup. Environ. Health 72:451-461.

Wolkoff, P., P. Skov, C. Franck, and L.N. Petersen. 2003. Eye irritation and environmental factors in the office environmenthypotheses, causes and a physiological model. Scand. J. Work Environ. Health 29:411-430.
Wolverton, B.C. and J.D. Wolverton. 1993. Plants and soil microorganisms: Removal of formaldehyde, xylene, and ammonia from the indoor environment. J. Miss. Acad. Sci. 38:11-15.

Yang, X., Y.P. Zhang, D. Chem, W.G. Chen, and R. Wan. 2001. Eye irritation caused by formaldehyde as an indoor air pollution: A controlled human exposure experiment. Biomed. Environ. Sci. 4:229-236. 